Diana Woodburn MSc, MBA, FCIM

is a founding director of MarketingBestPr@ctice and visiting fellow at Cranfield School of Management. Together with Professor Malcolm McDonald, she spearheads Cranfield's initiatives in key account management, including research projects, seminars and the KAM Best Practice

Research Club. She has written reports and articles, and coauthored a book entitled Key Customers with Professor McDonald. As an experienced practitioner and consultant in marketing and KAM with bluechip companies, Diana has worked in numerous sectors and countries.
Keywords: Cranfield University, key account management, research, marketing, consultant, director, B2B, B2C

\section{Diana Woodburn}

Marketing Best Pr@ctice Ltd Chiltern House

Thame Road

Haddenham

Bucks HP17 8BY

UK

Tel: +44 (0)1844295855

Fax: +44 (0)1844 295856

E-mail:

woodburn@marketingbp.com

\section{Customer relationship management: Hard lessons learned in B2B pose tough questions for B2C}

\author{
Diana Woodburn
}

Received (in revised form): 1 May 2002

\begin{abstract}
Business worldwide has gone through extensive consolidation and globalisation, so that many B2B companies now find that a very few huge customers contribute a crucial amount of their turnover. For them, key account management (KAM) is marketing, or effectively all the marketing that matters. Even companies with a more balanced customer base recognise that they survive or sink depending on their top 20 or 30 accounts. This degree of focus has inspired them to develop customer relationships that should be the envy of consumer marketers.

Obviously there are major differences between relationships with consumers and those with key customers: scale being the first to mind. Nevertheless, there are elements in KAM that, even if not directly transferable to relationships with consumers or smaller B2B customers, should prompt some hard questions for interactive marketers. B2B suppliers to giant customers have learned some expensive lessons, and it is these that this paper seeks to pass on to B2C marketers, so that they can avoid some of the pitfalls and develop realistic CRM strategies.

The paper shows how these key relationships can be classified in order to distinguish between them and the strategies that can be applied in them. It concludes that when relationship building is warranted, which is not with all or even a majority of customers, the supplier needs to be very clear that they have selected the right customers, who will be responsive and give an appropriate return on investment. The findings discussed here are underpinned by the research into KAM carried out by the author on behalf of Cranfield School of Management.
\end{abstract}

\section{KAM: The home of real relationships}

Perhaps it is time for CRM practitioners to look back at the basics, push the technology on one side and consider the true nature of relationships with customers. Perhaps, rather than arriving immediately at 'How can technology help us in our customer relationships?', which rather begs the question anyway, the question should be 'How can we improve relationships with our customers?' or even 'Do we want to have relationships with our customers?' While CRM (as the technology-based discipline it is now generally considered to be, rather than the generic 
While CRM has been developing around the software, KAM has been developing around its customers

\section{KAM is in better shape than CRM as an approach to customers that really grows shareholder value}

\section{Balanced reciprocity in relationships}

\section{To the extent that B2C CRM is driven by software and automation ... it may inhibit or even destroy relationships}

\section{Rules or people?}

approach to customer relationship management that it was when it started out) has been developing around the software, KAM has been developing around its customers. Some would argue that, as a result, KAM is in better shape than CRM as an approach to customers that really grows shareholder value.

DHL grew profitable business with its key customers at twice the rate of the rest of the customer base.

In contrast, the rate of CRM failure is greater than 50 per cent in the first year. ${ }^{1}$ The benefits of placing the Internet as an intermediary between supplier and customer have been a major focus of CRM. In fact, the benefits have largely been realised by the supplier, while consumers have often lost a good deal of the value they did have in the change from service to self-service. Meanwhile, in KAM, where customers are more vociferous and determined about what kind of relationships they want, suppliers have been nurturing a growing intimacy with their customers. Of course, the B2B situation is different from B2C, but there are still valuable lessons for CRM practitioners to learn from how blue-chip companies are handling their biggest and best.

\section{What make a real relationship?}

Why do supplier/buyer relationships thrive better in a KAM environment than under CRM? Does the difference stem from the underlying premise posed by the author, that real relationships are intrinsically reciprocal? Relationships seem to exist at an individual-to-individual level, or, in different terms, at an organisation-to-organisation level, but the author suggests that the organisation-to-individual relationship is illusory. Where organisational relationships are mediated by people, the individual may consider that they have a relationship with that organisation, but do they when, effectively, it is not the case?

To the extent that B2C CRM is driven by software and automation, leading to self-service rather than person-to-person service, it may inhibit or even destroy relationships. If people-to-people bonds are intrinsic to relationships, attempts to inject relationship-building mechanisms are doomed to failure as long as they lack the personal element. That is not to say that CRM does not offer a number of useful attributes to suppliers, like lower prices through cost savings and selective offers made through cross-selling, which are good business builders. However, they are not to be confused with relationship-building approaches, although they may deliver the required result, ie more profitable business.

One-to-one marketing ${ }^{2}$ harnesses the power of IT to deliver elements of the marketing mix at a more granular level, but, and this is an important distinction between B2C CRM and KAM, it is still rule-based, and the rules are segment-driven rather than genuinely responsive to individuals. One of the big questions for B2C/small B2B marketers must be whether their customers really require a relationship with their supplier and, if they do, should it be provided by a retailer or distributor who offers a 


\section{At the top level of key customer relationships ... suppliers are in the realm of 'zero tolerance' of customer loss}

\section{Zero tolerance of customer loss}

\section{Shrinking customer pool}

personal interface, or by the manufacturer/service provider? If the latter, can that be implemented in a way that achieves a relationship that is both real and worthwhile for both sides? Some of the lessons learned in KAM, and the methodologies developed to deal with the issues, may be useful to B2C marketers in tackling this fundamental question.

KAM always involves people in the relationship, and often large numbers of people, so it starts by tackling those questions head-on. The analysis is driven on a business-case basis, with each case individually researched and created. The obvious difference between the contexts of KAM and B2C CRM is the importance of the individual customer. A key customer is defined as one who has strategic importance to a supplier, unlike specific individual consumers, who are generally unlikely to have such great importance. A consumer segment may have great strategic importance for a supplier, but the supplier cannot have a relationship with a segment.

At the top level of key customer relationships suppliers are in the realm of 'zero tolerance' of customer loss, which is certainly a strong relationship driver. In theory, CRM in B2C can mess up relationships and lose customers, after which the company acquires new customers to replace the old and vows to do better next time. Clearly, this is hardly a good approach to customers, but it does appear to allow a leeway to B2C companies that is not an option with key B2B customers, who operate in an increasingly smaller customer pool.

Constant consolidation has made big customers even bigger.

Simultaneously, of course, the number of customers has shrunk until there are so few that the idea of losing a customer is almost unthinkable. Across all kinds of sectors - automotive, financial services, telecoms, electronics, retailing, chemicals and many more - companies have swallowed up competitors, customers, suppliers and strategic alliances and emerged as monstrous corporations. The car industry is typical of this trend, with the number of car manufacturers diminishing over the last 30 years from 37 to ten and still falling (see Figure 1). When the stakes are as high as this, suppliers have ample encouragement to introduce best practice in relationship management, so their approaches are worth investigation.

Pilkington Automotive (global supplier of glazing systems to the automotive industry) treats key customer management as a strategic imperative: there are only eight to ten customers left in the industry. Pilkington already has a relationship with each of them, even where it is not a current supplier. In a customer base as concentrated as this, they cannot afford a lack of customer focus: there is no pool of fresh prospects to compensate for a lost customer.

\section{Relationship hierarchy}

\section{Relationship stages defined}

Several schools of researchers have identified a hierarchy of relationships ${ }^{3-5}$ which provides a useful framework in understanding the interactions between buyers and suppliers (Figure 2). Over the last five 


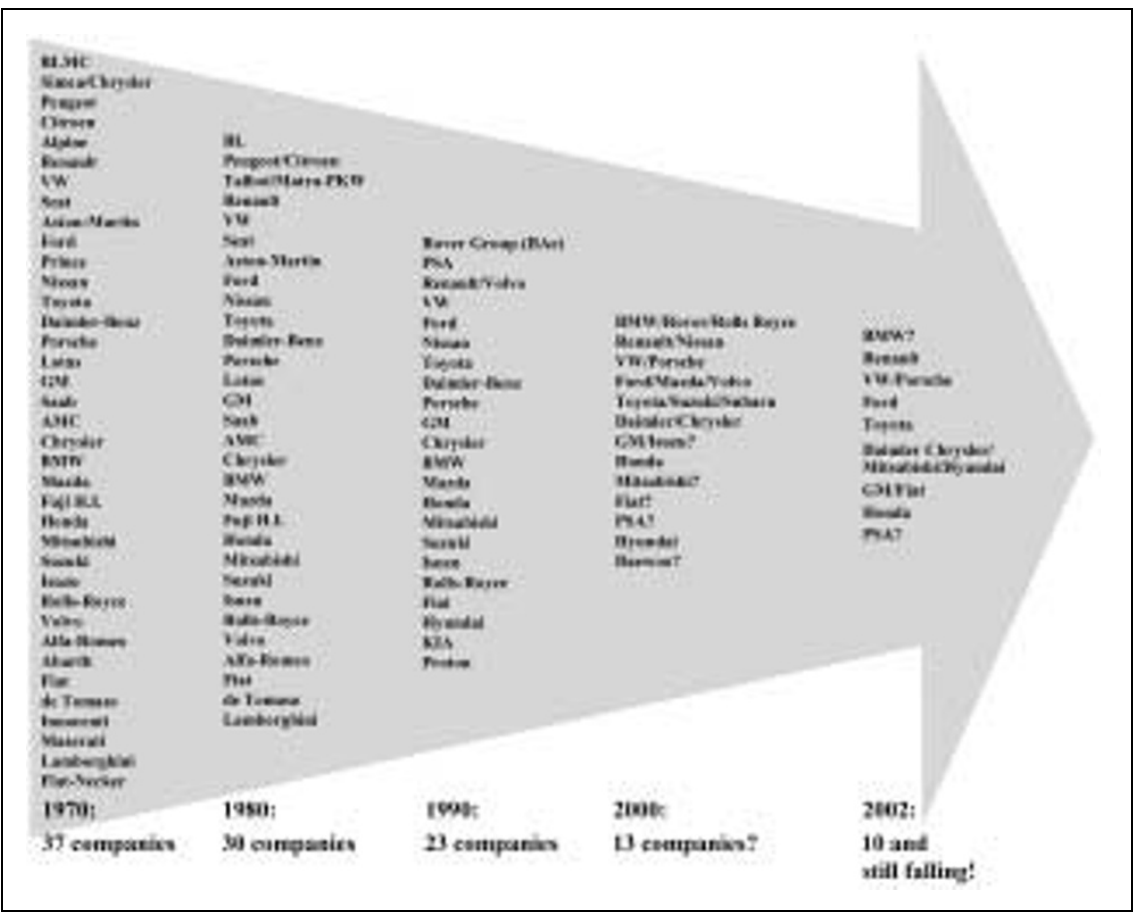

Figure 1: Consolidation in the global car industry

Reproduced with the kind permission of Peter Watters of Pilkington Automotive

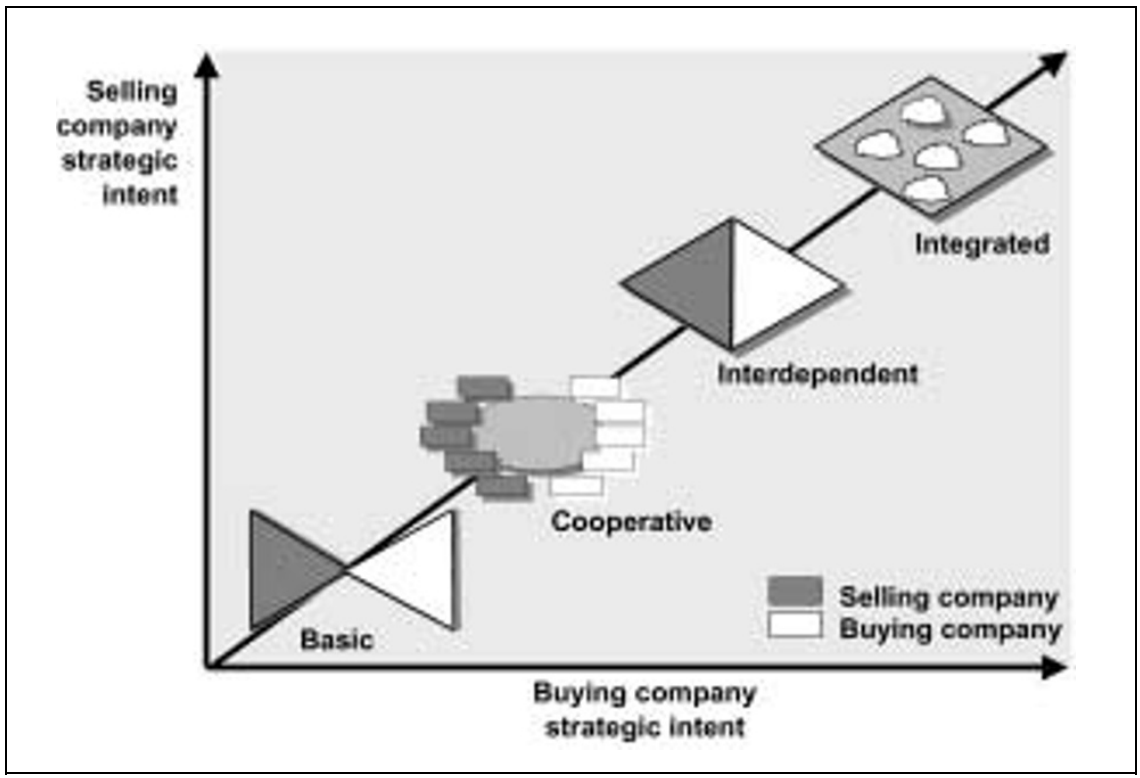

Figure 2: Levels of relationships with key customers Source: Millman and Wilson (see ref. 5)

years, Cranfield School of Management has been researching best practice in KAM, building up its understanding of these key relationships. ${ }^{6-8}$ Studies with suppliers and customers, involving interviews conducted with several management levels and functions, 


\section{Relationships range from single to complex}

\section{Price and efficiency \\ Price and efficiency
dominate the conversation}

\author{
Trial or long-term \\ option?
}

\section{Limited value add}




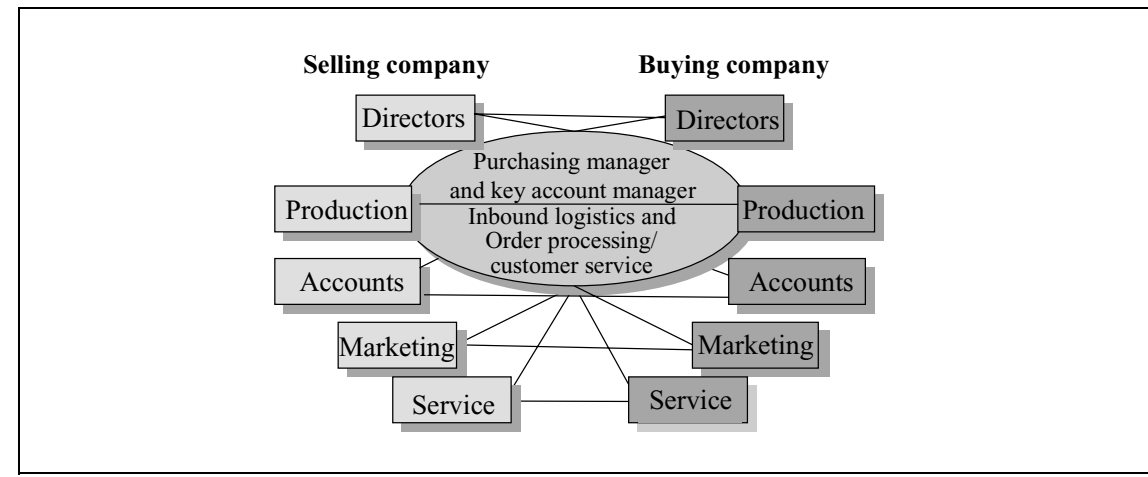

Figure 4: Cooperative relationships

often through its own experience after a period at basic KAM level. Opportunities to add value to the customer will be suggested by the supplier, and the buyer will adopt a positive and communicative attitude towards the supplier, perhaps in terms of indicating further opportunities to do business together, or helping the supplier to solve some of the operational problems that arise. The supplier is probably considered to be a preferred supplier. Contact involves a wider range of people and a greater exchange of information across a broader range of topics, but nothing particularly sensitive. The supplier is not really trusted, and the customer still sees exit as a fairly easy option.

\section{Interdependent relationships}

Trust and adaption

\section{Retreat is difficult, time-consuming and damaging}

At this stage, each understands and trusts the other, though not unconditionally. Both are prepared to invest in the relationship because they acknowledge its strategic importance. The selling company is the sole supplier, or at least the first option. The two parties are locked in to each other (Figure 5), not inextricably, but if the relationship were to end, retreat would be difficult, time-consuming and damaging. The supplier, and perhaps the customer too, adapt standard offers and processes where necessary to meet customer-specific needs, and they may have set up various initiatives together which would take time and effort to undo.

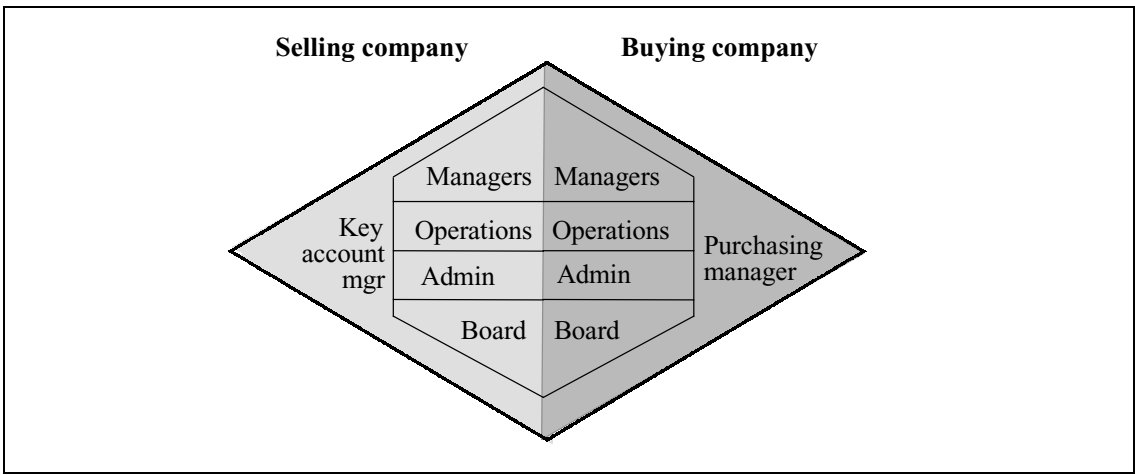

Figure 5: Interdependent relationships 


\section{Working together without barriers}

\section{Communication versus collaboration}

Both supplier and customer are involved in planning. A range of functions in both organisations are empowered to work closely together through a large number of 'touch points', orchestrated by, rather than channelled through, the key account manager and purchasing manager.

\section{Integrated relationships}

This stage of relationship involves openness and trust to a very high degree. Each lowers its protective barriers, on the assumption that the other will not take advantage of that potential vulnerability. For example, costs are transparent. The two companies work together as one entity in cross-boundary functional or project teams, and are even more entwined than at the interdependent stage (Figure 6). The teams run the business and plan their future, rather than either organisation, and they make decisions about their interactions with other teams according to the strategy they are implementing. Exit would be traumatic at both a personal and an organisational level.

One might think that a high volume of communication between two parties is a good indicator of a collaborative relationship, but it can be misleading. Krapfel et al. ${ }^{10}$ showed that where there is a high degree of common interest, but one side is more powerful than the other, there is indeed likely to be a large volume of communication, but this is of a largely directive nature on the part of the more powerful party, and does not indicate a collaborative relationship. The most stable and genuine relationships are found where the balance of power between supplier and customer is about equal and a high degree of common interest exists between the two, eg where both are committed to the same sector. So as the individual consumer just about never holds the balance of power, it is unlikely that they ever reach the 'higher' kinds of relationships, which are close, collaborative and mutually dependent, even where the communication volume is substantial.

\section{Customer profitability: Does relationship building make money?}

There is an expectation that closer relationships with customers will yield bigger revenues and lead to higher profits, not just in KAM but also in

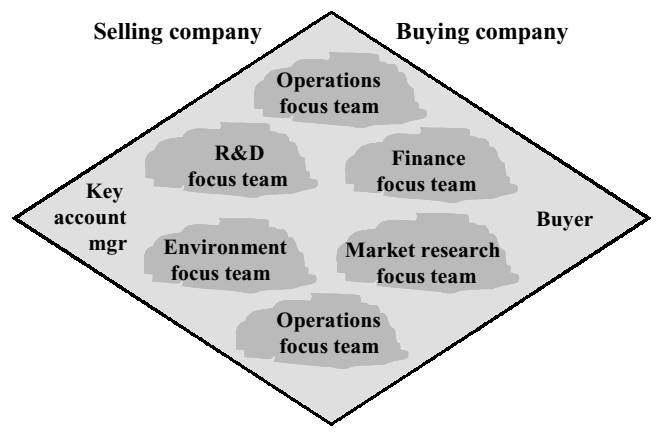

Figure 6: Integrated relationships 
A leading IT supplier ... grew its business with one key customer by 400 per cent over three years

\section{Profitability and relationship stage}

\section{Lessons from B2B}

CRM. But do they? Research from a number of sources shows that this expectation is not always fulfilled. ${ }^{11,12}$ On the other hand, outstanding results can be achieved, as ICL/Fujitsu proved by growing its business with one key customer by 400 per cent over three years, while maintaining profitability.

The Cranfield research suggests that problems with profitability are often linked to relationship stage. The customer's response to the supplier's overtures in terms of more business and help with cost savings is restrained until the customer begins to trust the supplier. However, trust only really begins to appear at the interdependent stage, and each stage of relationship is more expensive to manage and maintain than the one below it. Running the relationship at a cooperative stage can easily be eating up the profit that the business would have made at a basic stage. Figure 7 shows what the result may be.

As the seductive concept of relationship marketing took hold, a lot of B2B companies rushed into major relationship development programmes, assuming that the 'higher' levels of relationship were automatically better than the 'lower' ones. Indeed, as many B2C companies have made the same assumption, interactive marketers might want to look at the lessons learned by $\mathrm{B} 2 \mathrm{~B}$ companies which went in for relationship development across the board.

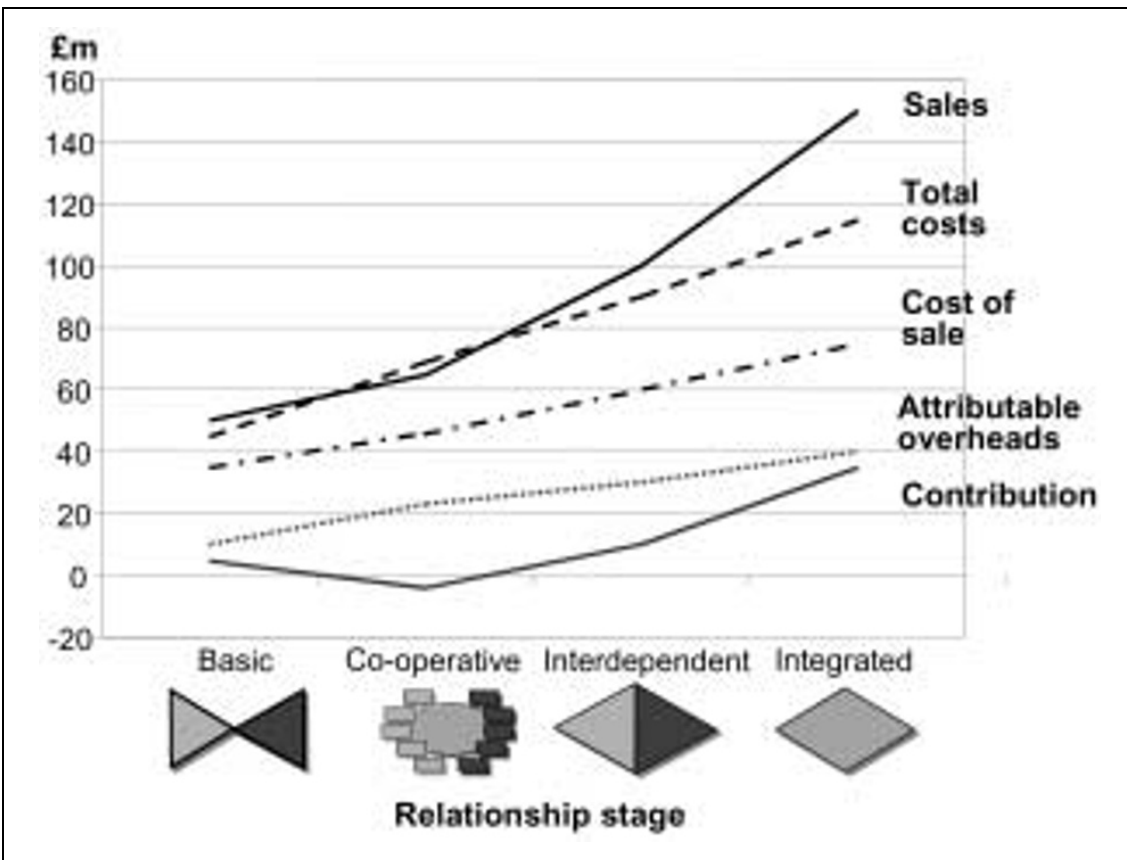

Figure 7: Relationships and customer profitability 
A financial services company realised that almost all of its relationships, including those with its biggest clients, were at a basic or transitional level. It targeted all its account managers on relationship improvement, at which they were rather successful, developing a high proportion to a cooperative stage. However, at the same time, profits slumped alarmingly. They rapidly reviewed the strategy and refocused it on to a far shorter list of clients.

\section{Reciprocity is crucial}

Some customers did not want, appreciate or respond to initiatives designed to bring them closer to the supplier. As far as they were concerned, there was no value to them in a more intimate relationship. If the purchase was peripheral to their interests, almost any relationship took up more time than they wanted to give to it. In fact, real intimacy was only required - or achieved - where the supplier was central to the customer's business.

\section{Relationships cost money}

After all is said and done, few people, if any, call the interaction between themselves and a computer 'a relationship'. They have relationships with people, which may be mediated or facilitated by electronic means. A relationship-building marketing mix needs people in it somewhere, and people are expensive. Their cost is even more obvious if the resource is drawn from elsewhere and the effect of its absence is clear, as in the example of the financial services company quoted above.

\section{Managing customers as a portfolio}

When the cost of relationship development is recognised, the natural conclusion is that the number being developed at any one time should be restricted, and balanced against those that are delivering a net cash outflow.

\section{A limited capacity for intimacy}

However large the company, and however deep its pockets are, it is unable to manage intimate relationships with all of its customers. Intimate relationships involve a dialogue, in which supplier and customer listen and respond to each other. As each round of dialogue reveals more of the customer's idiosyncrasies, the conversation will progress further away from the norm, demanding more special solutions to the needs expressed. Most companies can only handle a limited amount of deviation from their normal ways of working, and therefore a limited number of customers who require non-standard offers. What that number is requires careful consideration.

A global services company started its KAM programme with about 20 customers on the list. The programme was so successful that it was expanded to 250 worldwide. The company then realised that 
with these numbers it could not offer the benefits to key customers that had made the KAM approach so successful in the first place, and risked jeopardising the gains it had made. Numbers were cut back by 65 per cent, which was difficult and still more than ideal.

\section{Special customers expect special offers}

To key customers, special means having something different. So if they believe they have a special relationship with their supplier, they are expecting a materially different offer, not what everyone else gets. Having extra attention and understanding is nice, but only the start point, not the end point. Being given a relationship manager is irritating and frustrating unless he/she has the authority to deliver what the customer wants, and the supplier has the capability to match.

\section{Key customers should be carefully chosen}

For all the above reasons, it makes sense to make very careful choices about who does - and who does not - receive this level of service. As key customers should be very carefully selected and few in number, proper and appropriate management for those not selected is mandatory.

\section{Tough questions for B2C marketers}

These points probably all look sensible and fairly obvious. However, if the same conclusions are drawn for relationships with consumers or smaller $\mathrm{B} 2 \mathrm{~B}$ customers - and there does not seem to be a reason why they should not be - they pose some big questions for B2C interactive marketing.

\section{Issues for B2C}

- Can suppliers really get close enough to consumers to build a trustbased, mutually dependent relationship based on a deep understanding of the customer?

- If they cannot, does what they can do amount to a relationship in the customer's eyes?

- Do the kind of relationship levels that are available offer significant, business-building advantages over what went before?

- Can databases hold the kind of information that equates to a deep understanding of the customer, technically and legally? Realistically, can the supplier respond to it anyway?

- If close relationships can be developed, do they require multi-channel involvement, including person-to-person contact? Are suppliers able to provide the resources and handle a broad range of interaction?

- Do the costs of relationship development justify the extra business, or do they eat up the additional profit or, worse, the profit that the customer previously yielded?

- Does developing relationships just raise unrealistic expectations on both sides? Do customers then expect a level of customisation that is not economically or operationally possible? Do suppliers then expect a greater boost to business that extra contact alone will not deliver? 
- Does building relationships with consumers destroy shareholder value?

\section{Suppliers tend to deceive themselves about the level of relationship they have reached with a customer}

\section{Individually special offers expected}

\author{
One-sided \\ relationship \\ strategies are \\ expensive, wasteful \\ and ultimately \\ pointless
}

Before rushing to answer these questions for consumer relationships it is worth remembering the point made earlier, that the Cranfield research in KAM identified a phenomenon that was dubbed 'supplier delusion': suppliers tend to deceive themselves about the level of relationship they have reached with a customer, by about one of the stages described above. Consumer relationship marketers may well harbour the same misperception and construct misleading expectations on it.

Even if it is possible to build real relationships with consumers, it may well be that the effort required will never fulfil ROI criteria, and that interactive marketing strategies should be developed with a focus on operational efficiency rather than relationship building. In KAM, and there is no reason to suppose that consumers see things differently, customers place very limited value on extra, friendlier, more frequent or even more accessible contact unless it leads on to an offer substantially different from what is normally available to them.

However, it may be that real relationships with consumers are worthwhile and achievable, but only in certain circumstances. The supplier would be looking for exceptionally attractive individuals who are particularly engaged with their purchase. In that case, identifying those individuals becomes crucial.

\section{Which relationships should be developed and which not?}

Realistic relationship aspirations should depend on both supplier and customer: suppliers should carefully select customers with the right profile, based on their business potential, and then verify with each customer that they wish to be involved in this kind of relationship. Commitment on both sides is absolutely essential to success. One-sided relationship strategies are expensive, wasteful and ultimately pointless. To identify the relationships that should be developed, many suppliers are using a version of the directional policy matrix..$^{13-15}$ One axis captures the supplier's view of the customers, and the other captures the customer's view of the supplier (see Figure 8).

The matrix indicates the overall strategic approach to each customer. For example, there may be customers who are unremittingly price focused but are still very large and important to the critical mass of the supplier. 


\section{Determining the strategic mix}

\section{Mapping strategies and relationships}

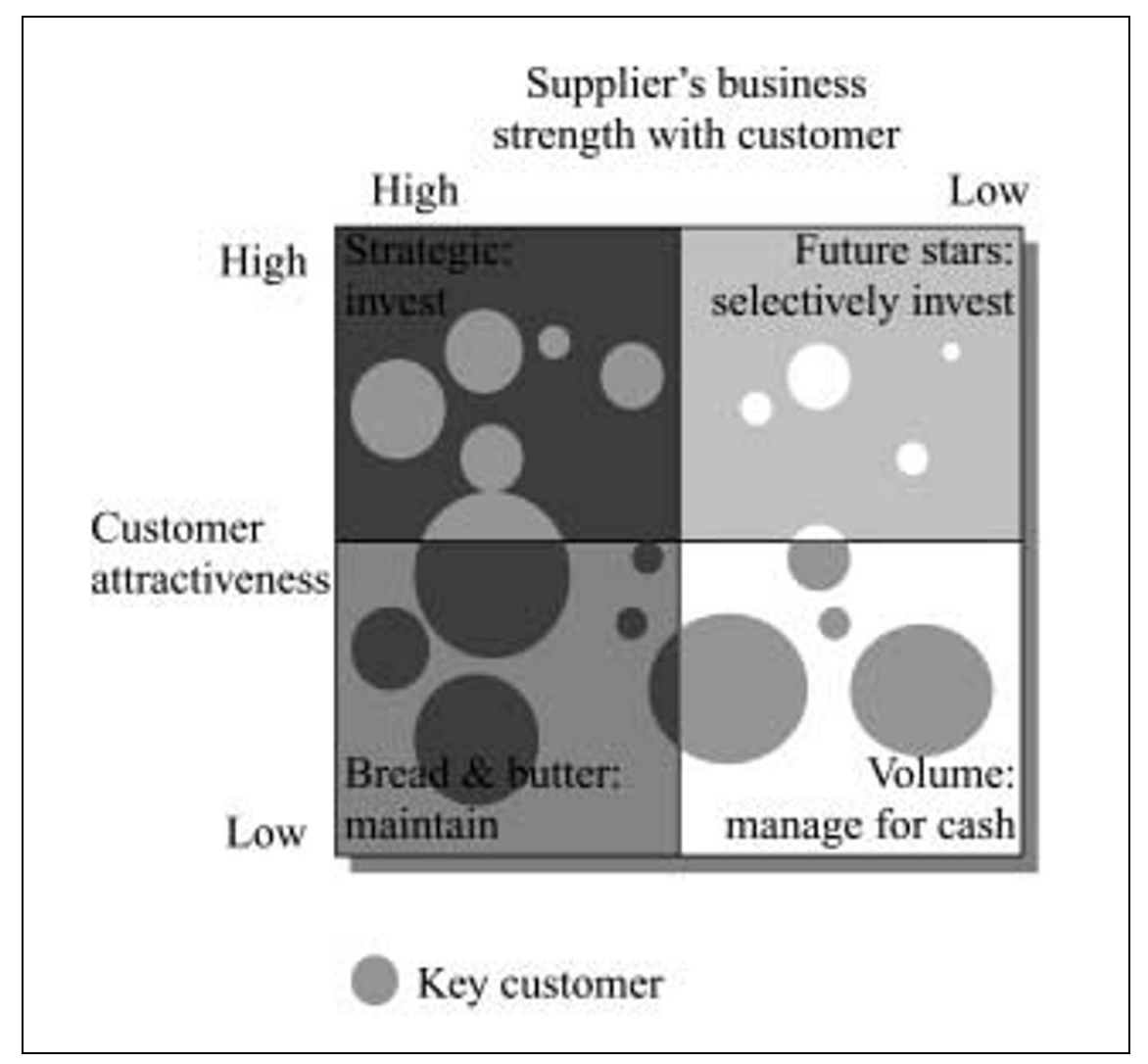

Figure 8: Key account selection and categorisation matrix

Nevertheless, their potential looks poor and they do not value relationships (bottom right of the matrix), so they should be handled with a strong bias to efficiency. In such a case, marketing range and effort should be limited: the supplier may not want to lose the customer, but it should not invest much, as putting resources into the customer would undermine profitability and achieve a poor return.

In contrast, a key customer who is aligned to the supplier strategy, is already sizeable and has strong potential for growth, and genuinely wants to work in partnership with the supplier (top left of the matrix) should be offered the whole 'rich mix' of KAM, facilitated and even driven by extensive and excellent communications.

Customers for development (top right of the matrix) need an entrepreneurial approach and investment, carefully monitored for signs of response. Those customers in the bottom left of the matrix should be strong cash generators: they are often the stars of the past, still good customers but unlikely to grow. They need excellent management on a maintenance rather than an investment basis.

The kind of relationships that would be suitable for each strategy can readily be mapped on to the quadrants. Close relationships like interdependent or integrated are necessary for strategic customers in the top left. There may also be a legacy of interdependent relationships with customers in the bottom left, which is fine if carefully managed and 
controlled. For development customers (top right), a cooperative relationship is likely, moving towards an interdependent stage if the business develops as anticipated. However, for customers whose potential is limited and who are relatively unattractive to the supplier, and who do not rate the supplier highly either, a basic relationship is appropriate. Attempts to develop it beyond that are misguided and likely to be costly as well, though many companies find this hard to accept and implement this approach consistently.

A global manufacturing company said 'We throw more at our worst customers than the others, in spite of the relationship.'

\section{Unless a really close relationship can be achieved, suppliers struggle to make a return on the costs of relationship development}

\section{Marketers can invest a ton of money in new technology... and still discover that the customer regards it as a precursor to further material benefits}

\section{Challenging relationship building}

\section{Finding the right customers}

\section{Conclusions}

The exciting philosophy of relationship development has prompted many marketers to seek to develop relationships with their customers across the board. The Cranfield research into KAM shows that, in many cases, this is both expensive and ineffectual, and may pose a serious threat to shareholder value. Unless a really close relationship can be achieved, suppliers struggle to make a return on the costs of relationship development, even with very big customers.

Why should consumer relationships be different? Developing relationships with consumers costs money as well, and the theory that technology lowers those costs should be carefully scrutinised. The experience of suppliers to key customers is that new channels of interaction can save cost, but also that they only account for a part of the cost of managing and building the relationship, and not necessarily the major part either. As the relationship develops, so do the customer's expectations of it, and they are not all satisfied by the application of technology. The costs of satisfying these other demands can easily outstrip the savings made through IT. Marketers can invest a ton of money in new technology and the people to run it properly, and still discover that the customer regards it as a precursor to further material benefits, and does not yet feel any more bound to them than before.

So the big question for interactive marketers is 'Is relationship building wasted on any of our customers, and if so, how many and who?' The next question has to be 'Do we need relationships with our customers? Is relationship development the right strategy for us, or should we be aiming at something else?' Red-hot lead management, efficient cross-selling, product innovation and excellent delivery are all alternatives that might offer a better return on investment. Basic relationships may well be successful, and if the customer is not engaged with the purchase, or focused on low cost, or known for supplier switching and unresponsive to added value, or if any changes in the environment may limit the length of life of the relationship, then it may be best to maintain it at this level.

If relationship building does appear to be justified, there is still the question of which customers are targeted, as clearly not all will be responsive and worthwhile. This raises the subsidiary question of how 


\section{Sharing the KAM experience}

suitable candidates for relationship development are selected, and how they indicate their willingness to commit, or otherwise. Many companies are still struggling to become more objective about selecting customers for KAM, but a few are beginning to apply value-based management (VBM) to individual customers very successfully and placing them in strategic categories on this basis.

Indeed, the whole idea of developing relationships with customers is rooted in the way suppliers nurtured their biggest customers, out of clear necessity even before it was called key account management, so KAM has a good deal to offer interactive marketers in developing customer relationships. $^{16}$

\section{References}

1. Moscardini, N. (2001) Proceedings of E-CRM Summit, Worldtrade Group, Gartner Group, London.

2. Peppers, D. and Rogers, M. (2001) One-to-one B2B - Customer Development Strategies for the Business-to-business World, Doubleday, New York.

3. McDonald, M., Millman, A. and Rogers, B. (1996) Key Account Management - Learning from Supplier and Customer Perspectives, Cranfield School of Management, Cranfield.

4. Dunn, D. T. and Thomas, C. A. (1994) 'Partnering with customers', Journal of Business and Industrial Marketing, Vol. 9, No. 1, pp. 34-40.

5. Millman, A. and Wilson, K. (1994) 'From key account selling to key account management', paper presented to Tenth Annual Conference on Industrial Marketing and Purchasing, University of Groningen, Netherlands.

6. McDonald et al., ref. 3 above.

7. McDonald, M. and Woodburn, D. (1999) 'Key account management — Building on supplier and customer perspectives’, Financial Times Prentice Hall, Edinburgh and London.

8. McDonald, M. and Woodburn, D. (2001) Key Customers World-leading Key Account Management: Identification and Development of Strategic Relationships, Cranfield School of Management, Cranfield.

9. McDonald et al., ref. 3 above.

10. Krapfel, R. E., Salmond, D. and Spekman, R. (1991) 'A strategic approach to buyer-seller relationships', European Journal of Marketing, Vol. 25, No. 9, pp. 22-37.

11. McDonald et al., ref. 3 above.

12. Wilson, C. (1997) Profitable Customers, Kogan Page, London.

13. McDonald et al., ref. 3 above.

14. Zolkiewski, J. and Turnbull, P. (2000) 'Key account management, customer portfolios and networks: Academic rhetoric or practitioner tools?', in Proceedings of 4th International Symposium on Selling and Major Account Management, Sales Research Trust.

15. Fiocca, R. (1980) 'Account portfolio analysis for strategy development', Industrial Marketing Management, April, pp. 53-62.

16. McDonald, M., Rogers, B. and Woodburn, D. (2000) Key Customers: How to Manage Them Profitably, Butterworth-Heinemann, Oxford. 